\title{
Wages and Health Worker Retention: Evidence from Public Sector Wage Reforms in Ghana
}

\author{
James Antwi \\ Greenwich School of Management \\ University of Wales
}

\author{
David Phillips ${ }^{1}$ \\ Department of Economics \\ Georgetown University
}

February 2011
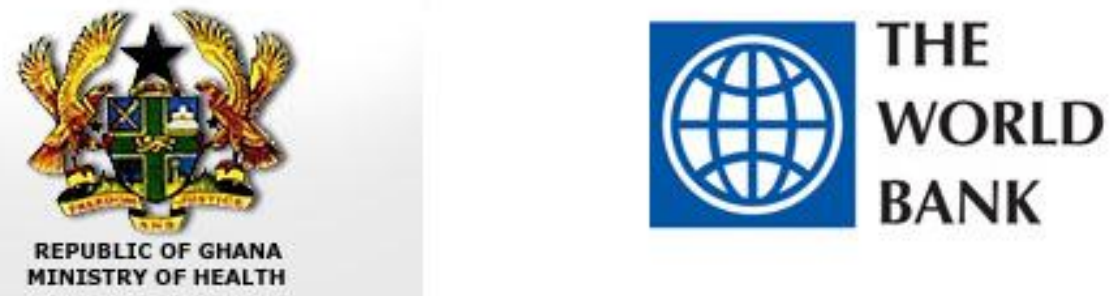

\footnotetext{
${ }^{1}$ Corresponding author; can be contacted at dcp34@georgetown.edu. We have valued feedback from Michael Clemens, Garance Genicot, Billy Jack, Arik Levinson, Anna Maria Mayda, and seminar participants at the 2010 NEUDC Conference, the Georgetown Public Policy Institute Development Workshop and the Georgetown Graduate Student Seminar. We would also like to thank Dr. Ebenezer Appiah-Denkyira, Margaret Chebere, Victor Ekey, and staff at the Ministry of Health, Ghana Health Service, Nurses and Midwives Council, and CAGD that assisted by providing data and insight. We are also grateful to Chris Herbst, Karima Saleh, Agnes Soucat, and others in the World Bank (AFTHE) for their support. During this research, Mr. Phillips worked for the World Bank (AFTHE) as a consultant and Mr. Antwi worked for the Ghana Ministry of Health. The opinions expressed herein do not necessarily reflect those of the World Bank or the Government of Ghana. All errors and omissions remain the responsibility of the authors.
} 


\begin{abstract}
Can governments in developing countries retain skilled health workers by raising public sector wages? We investigate this question by way of a policy-induced natural experiment, in which the Government of Ghana restructured the pay scale for health workers employed by the government. We find that a ten percent increase in wages decreases annual attrition from the public payroll by 0.9 to 1.6 percentage points (from a mean of about 8 percentage points) among 2040 year-old workers from professions that tend to migrate. We find that these effects are concentrated among young workers, and we detect no effects among categories of workers that do not tend to migrate. Given Ghana's context as a major source of skilled health professional migrants and high correlation of our attrition measure with aggregate migration, we interpret these results as evidence that wage increases in Ghana improved retention mainly through reducing international migration.
\end{abstract}

JEL Codes: O15, F22, J45, J61, and H51. 


\section{Introduction}

High attrition of skilled employees can generate under-staffing in the public health care systems of developing countries. Wage differentials between domestic public employment and other options are one factor that could be driving doctors, nurses, and other skilled health workers to leave the public health sector, often for jobs in high-income countries. Knowing the impact of wages on attrition takes on particular importance when responding to the migration of health workers from low and middle-income to high-income countries. Though the appropriate response to this trend is oft-debated, many developing countries have decided to take policy positions discouraging such migration. Increased salaries represent one possible but expensive option for improving retention. Knowing the impact of increased salaries on migration provides vital information to policy makers considering the costs and benefits of raising salaries as opposed to mandatory public service, improved facilities, shifting from higher to lower skilled health workers, and other options.

Despite the importance of this issue to policy makers and the centrality of wages in the basic economic model of migration, little strong evidence exists on the causal impact of home country wages on attrition of health workers. This paper aims to isolate the causal effect of wages on attrition by use of a natural experiment. In the ideal econometric situation, wages would be set randomly so that any correlation between wages and attrition would be causal. Lacking this situation, we exploit a sudden change in the compensation of different groups of public sector health workers in Ghana. As a result of this policy change, health workers of different categories and different levels of experience received widely varying pay increases. Paired with administrative data, we use this natural experiment and a difference-in-differences strategy to test whether the groups of health workers who received the largest raises had their attrition rates fall the most.

We find that, on average, higher wages do decrease attrition of health workers from Ghana's public payroll. A ten percent increase in wages decreases annual attrition by 0.9 to 1.6 percentage points (10 to 20 percent of the mean) among 2040 year-old potential migrants. We find evidence that this effect is concentrated among the youngest workers (20-35 years old) and no evidence that wages affect attrition for mid-career potential migrant workers (35-55 years old). Among categories of workers that rarely migrate, we find no evidence of wages reducing attrition for early-to-mid career workers. During this time period, Ghana was a major source of high-skilled health worker migrants, and measures of health worker migration correlate strongly with our measure of attrition at aggregate levels. Thus, we interpret the results as most plausibly capturing the effect of wages in reducing international migration. Finally, we also detect an impact of wage increases in reducing attrition among late-career workers from both potential migrant and non-potential migrant categories. We attribute this effect to reducing attrition from retirement.

Our main results confirm the predictions of simple models of migration and employee retention. In the simplest migration models, an increase in home 
country wages unambiguously reduces the probability that an individual will migrate by reducing the 'push' effect of a large wage gap (Borjas, 1987). Similarly, on-the-job search models of employee retention predict that an employer with higher wages will retain workers for longer by competing more effectively with other employers (Burdett and Mortensen, 1998). While confirming the most basic models, our results contrast with simple model extensions that can counteract or even reverse the effect of higher wages. In models of migration, home wages can encourage migration by making it possible to overcome credit constraints that prevent financing migration costs (Lopez and Schiff, 1998). In our context, higher wages lead to higher future pensions as well. So, in job search models, higher wages could have wealth effects that encourage retirement or other decreases in labor supply. From the standpoint of these theories, the impact of wages on attrition is ambiguous. Our results indicate that the net impact of wages on attrition is negative, i.e. the incentive to stay provided by higher wages dominates such credit or labor supply effects.

The remainder of the paper is as follows: section II describes Ghana's health sector and the 2006 wage reforms; section III provides a short discussion of the theory; section IV briefly reviews pertinent literature; section V describes our identification strategy; sections VI and VII describe the data and the results. Finally, section VIII explores some robustness checks and section IX concludes.

\section{Background}

\subsection{Migration of Health Workers from Ghana}

Ghana has long been a major source of migrants in the health sector. Likely due their high quality training, low wages, and English proficiency, many Ghanaian health workers have left for jobs abroad. Bhargava and Docquier (2008) provide cross country data on physician migration into OECD countries. As shown in Figure 1, in an average year from 1991-2004 three to four percent of Ghana's physicians migrated annually, easily outpacing the African average. Prior to this time period, migration rates were even higher, with Dovlo and Nyonator (2003) reporting annual migration rates of 10 to 20 percent for graduates in the 19851994 classes of the University of Ghana Medical School. As shown in Table 1, these migrants mainly leave for English-speaking, high-income countries. Data from the Ghana Nurses and Midwives Council indicate that a full 71 percent of nurses leaving during 2002-2005 went to the UK, with most of the remainder leaving for the US. Data from Dovlo and Nyonator (2003) indicate a similar pattern for physicians.

After multiple decades of extensive migration by Ghanaian health workers, flows of health workers out of Ghana have slowed in recent years. Figure 2 demonstrates this fact for nurses using Nurses and Midwives Council data and administrative payroll data. Ghana's Nurses and Midwives Council keeps

statistics on the number of requests by domestically trained nurses to have their credentials verified for international employment. As the figure indicates, migra- 
tion of nurses from Ghana plateaued in the early 2000's, dropped precipitously in 2006, and then leveled off at a reduced rate. Attrition of nurses under age 40 from the public payroll shows a similar pattern. In the same figure, attrition rates show a large drop in 2006 and subsequently stabilize, closely following the NMC migration data. Recent decreases in migration are also apparent for physicians, as depicted in Figure 3. Attrition from the public sector and data on new Ghanaian registrants to the UK's General Medical Council show a strong correlation with each other as well as a drop in 2006. The close correspondence between migration data and attrition from the public payroll will be important later for the interpretation of our results. Because individual-level migration data is unavailable for our sample, we will use attrition from the public payroll as our dependent variable. The time-series correlation of our dependent variable with migration measures provides an indication that attrition in our data is best interpreted as migration.

The recent, sudden decline in migration of health workers from Ghana begs the question as to its causes. As Figure 4 shows, health workers migrating to the UK can roughly double their earnings, even after adjusting for purchasing power differences. For example, doctors in Ghana earned about 1,000 Ghana Cedis per month but could earn about 2,500 Ghana Cedis per month (PPP) in the UK. Many point to such wage gaps as the main cause of migration of skilled health workers to high-income countries. In 2006, at precisely the same time as the fall in migration, the government of Ghana introduced a new wage structure for health workers that increased earnings significantly for many health workers. While many other factors and policies in Ghana and abroad likely influenced the decline in migration, we will focus on isolating the role that wages played.

\subsection{Public Health Sector Wage Changes in Ghana}

In Ghana, as in many sub-Saharan African countries, the public health system and religious non-profit hospitals together comprise most of the health sector. In Ghana, the public health sector is mainly composed of the Ministry of Health $(\mathrm{MOH})$, the Ghana Health Service (GHS), and the two main teaching hospitals: Korle Bu in Accra and Komfo Anokye in Kumasi. In addition to these facilities, some health workers are posted to military and prison hospitals. The Christian Health Association of Ghana (CHAG) provides most of the non-profit health services in the country. Together, the $\mathrm{MOH}$ estimates that these two sectors employ 90 percent of all health workers in Ghana. Most of the remainder work in the private for-profit health sector. Importantly for this study, the central government pays the salaries of both public and CHAG employees. Payroll records for employees of these agencies are kept at the Controller and Accountant General Directorate (CAGD) in Accra. Our data will cover all workers in this database who fall under $\mathrm{MOH}$, i.e. all health workers in the country except for those in the for-profit private sector and those employed at prison and military hospitals. MOH estimates that the employers in our database employ 82 percent of health workers in Ghana.

In 1998, the Ministry of Health introduced the Additional Duty Hours Al- 
lowance (ADHA) for health workers. As its name implies, the ADHA's explicit purpose was to compensate doctors, nurses, and other core clinical workers for unusually long hours. However, shortly after its creation in 1998, the ADHA became a simple salary supplement and was extended to other cadres of health workers. The Ministry of Health (MOH) assigned a fixed number of notional hours to each cadre (doctor, professional nurse, etc.) of employee, and all employees in the same cadre received the same number of hours. Since these hours were paid at the worker's usual hourly rate, the ADHA amounted to a percentage bonus of a health worker's base salary. Within a cadre all employees received the same percentage bonus from ADHA, while different cadres received different bonuses due to differences in notional hours assigned. This system, supplemented by common percentage pay raises among all employees, ensured that the relative pay of all healthworkers was stable from 2000-2006.

In 2006 due to budgetary pressure, the Government of Ghana desired to fold the ADHA into regular pay. Health workers also pushed for ADHA to be converted into basic salary because the ADHA payments were often delayed and were not taken into account when determining pensions. Since ADHA had grown to be a very large proportion of many health workers' pay, the government decided to adopt an entirely new salary structure, the Health Salary Structure (HSS). Pay rates under the new schedule were defined based on a job evaluation that arranged different jobs in the new salary structure according to the skills and tasks of the job. As a result, the new salary structure gave nominal wage increases of varying degrees to all health workers, but due to inflation and the loss of ADHA, some workers saw their real total earnings rise slowly or even drop. Importantly, due to differences in the raises assigned to various groups of workers and due to the fact that some cadres benefitted more from ADHA than did others, the new salary structure completely rearranged the relative pay of many workers. Finally, as a part of the arrangement made in adopting the HSS, workers' nominal wages were frozen from 2006-2009.

Figure 5 displays these wage changes. In the wage schedule, a health workers' pay is determined by 'grade' and 'step.' Grades differentiate large promotions (principal nursing officer, medical officer, senior medical officer, specialist, etc.) while steps embody smaller promotions within a grade. In the figure, each line represents real log wages (inclusive of ADHA) for each possible gradeXstep combination, normalized to zero in 2003. Thus, following an individual line over time traces the wages of a worker that is never promoted from 2003-2009. From 2003-2005 the lines generally move together, demonstrating that all groups of workers received common percentage wage increases. But from 2005 to 2006, the wages of different groups of workers diverge. Some workers received real wage increases of up to 50 percent while others even saw their real wages decrease by up to 30 percent. We will exploit the variation in wages across professions, seniority, and time generated by this policy change to measure the impact of wages on attrition. 


\section{A Simple Theoretical Framework}

\subsection{A Simple Model of Migration}

Consider an individual choosing between continuing to work in the public health system and leaving for another job. We will interpret this other option as migrating for a job outside the country, but in principle the outside job could be in the private health sector or outside the health profession. Assuming a linear indirect utility function, an individual $i$ will attrite at time $t$ iff:

$$
\begin{gathered}
\alpha_{0}+\beta_{1} w_{i t}^{*}+\delta_{0} x_{i t} \geq \alpha_{1}+\beta_{2} w_{i t}+\delta_{1} x_{i t}+c_{i t} \\
\Leftrightarrow c_{i t} \leq \beta_{0}+\beta_{1} w_{i t}^{*}-\beta_{2} w_{i t}+\delta^{\prime} x_{i t}
\end{gathered}
$$

where $c_{i t}$ is the cost of migration, $w_{i t}^{*}$ is the log wage abroad, $w_{i t}$ is the log wage at home, and $x_{i t}$ is a vector of individual characteristics that are valued differently at home and abroad ( $\delta$ is the marginal value of an attribute abroad relative to home). If $F$ is the distribution of $c_{i t}$ then the probability of attrition $A_{i t}$ is:

$$
A_{i t} \equiv \operatorname{Pr}[\text { Attrition }]=F\left[\beta_{0}+\beta_{1} w_{i t}^{*}-\beta_{2} w_{i t}+\delta^{\prime} x_{i t}\right]
$$

In this simple model, the impact of home wages on the probability of attrition is unambiguously non-positive. Assuming $F$ is differentiable with density $f$ :

$$
\frac{\partial A_{i t}}{\partial w_{i t}}=-f\left(\beta_{0}+\beta_{1} w_{i t}^{*}-\beta_{2} w_{i t}+\delta^{\prime} x_{i t}\right) \times \beta_{2} \leq 0
$$

However, even in this model the magnitude of the impact of wages depends greatly on the functional form and support of $F$. In particular, if the wage gap is very large between the home and foreign countries, then the impact of wages will be likely be small. Intuitively, large wage gaps move us into the 'tail' of the distribution of migration costs. ${ }^{1}$ In the case of health workers migrating from Ghana to their main destination in the UK, this could very well be the case. In fact, some policy-focused research discourages salary increases as a method for decreasing health worker migration from sub-Saharan Africa due to the perception that salary increases will likely be ineffective due to the large wage gaps (Vujicic, et. al., 2004).

\subsection{Credit Constraints}

The unambiguous negative impact of home wages on attrition disappears if a simple credit constraint is added to the model. In an extreme case, suppose that a worker receives the public sector wage at time t. Then, the individual can choose whether or not to leave, expecting that future wages will be the same as today. Finally, suppose that the cost of migration must be financed out of current wages. Then, for an individual to migrate, they must be able to finance migration:

\footnotetext{
${ }^{1}$ Formally, as long as $\lim _{w^{*} \rightarrow \infty} f(\cdot)$ exists, then it must be zero. As a result, the limit of $\frac{\partial A_{i t}}{\partial w_{i t}}$ must be zero as well.
} 


$$
c_{i t} \leq w_{i t}
$$

Thus, an individual attrites iff (1) and (2) both hold, i.e. the probability of attrition is

$$
A_{i t}=F\left[\min \left\{w_{i t}, \beta_{0}+\beta_{1} w_{i t}^{*}-\beta_{2} w_{i t}+\delta^{\prime} x_{i t}\right\}\right]
$$

For individuals with low wealth, wage increases may actually lead to higher migration rates:

$$
\frac{\partial A_{i t}}{\partial w_{i t}}=f\left(w_{i t}\right) \geq 0 \quad \text { if } w_{i t}<\beta_{0}+\beta_{1} w_{i t}^{*}-\beta_{2} w_{i t}+\delta^{\prime} x_{i t}
$$

Thus if a change in home wages reflects both an increase in current wages and a similar increase in expected future wages, the sign of the marginal effect of home wages on migration is an empirical question as well.

\section{Literature Review}

A growing literature attempts to identify and measure the determinants and impacts of medical migration from developing countries. Much of this literature focuses on the impact of migration on health outcomes in the sending country (e.g. Clemens, 2007; Bhargava and Docquier, 2008). The literature on determinants remains largely qualitative. Two quantitative papers by Okeke (2009) on the determinants of physician migration in Africa come closest to our topic. These studies use cross-national comparisons to examine the impact of growth shocks and the introduction of the ADHA in Ghana on physician migration. We take a different approach to measuring the impact of wages on migration by using micro data to examine the impact of a well-defined policy change on individual decisions.

Our study is also related to the extensive literature on the determinants of migration, in general. The cross-country panel literature on the determinants of migration generally proxies home country wages with home country GDP per capita. These studies rarely detect a statistically significant impact of home country wages on migration. Most studies suggest that this is likely due to opposing incentive and credit constraint effects. However, it is difficult to test this proposition cleanly using macro data, though some studies find evidence that higher GDP correlates with more migration from the lowest income countries and less migration from higher income countries (e.g. Clark, et. al., 2007; Pederson, et. al., 2004). These studies help clarify the correlations across countries but often have difficulty providing results with a reasonable causal interpretation; however, some studies move in this direction by using country fixed effects and lagged GDP (Mayda; 2008). We hope to move further in this direction using an identification based on micro-data and a natural experiment. We will also be able to measure wages directly rather than proxying with GDP.

Studies using individual-level data attempt to measure the causal impact of wages while removing bias caused by unobserved ability and other factors. Gibson and McKenzie (2010) attempt to eliminate this bias by focusing on a 
very narrow group of very highly-skilled individuals: valedictorians and Science Olympiad participants. This helps address endogeneity, but as they acknowledge, this approach necessarily limits the external validity of the results. Other studies attempt to eliminate the bias by modeling selection into migration parametrically. This approach to selection, unfortunately, often requires strong assumptions about the parametric form of unobservables that cannot be verified.

A few papers have applied a natural experiment methodology to questions related to migration and wages. Yang and Choi (2007) find that rainfall-induced income shocks in the Philippines cause increased migration from households that were previously unable to send migrants abroad. Similarly, Angelucci (2005) argues that randomly provided cash transfers from the PROGRESA experiment encourage some household members to migrate by relaxing credit constraints of the recipient households. Both of these studies find interesting evidence suggesting a role of income in relaxing credit constraints to migration in two particular contexts. Whether this result applies widely to many situations remains an interesting open question. In the literature on return migration, Yang (2006) exploits quasi-random variation in exchange rates caused by the Asian financial crisis. He finds that reduced returns to working in the foreign country result in more return migration.

Finally, because we relate wages to attrition from the public payroll, the literature on employee retention is pertinent to our study. Models of on-thejob search (Burdett and Mortensen; 1998) rely on a margin-volume tradeoff whereby offering higher wages results in attracting and retaining more workers. Our results can also be interpreted as evidence for such a tradeoff.

\section{$5 \quad$ Identification Strategy}

\subsection{Main Identification}

Finding exogenous variation in wages is important for a study of migration and home wages because the correlation between wages and migration can rarely be interpreted as the causal impact of wages. Individuals with high ability generally receive higher wages and migrate more frequently (Hanson, 2008). As a result, the correlation across individuals between home wages and migration will not reflect the causal impact of wages on migration. Meanwhile, the correlation between migration and wages across different locations will also not generally reflect the causal impact of wages because causality also runs the other direction: migration is a supply shock potentially affecting wages.

The wage reforms described above help alleviate these difficulties. The scene depicted in Figure 5 closely mimics an experiment with variation in the intensity of treatment. Conditional on time fixed effects, dummies for each gradeXstep combination, and no promotions, the vast majority of the variation in wages occurs as a result of the policy-induced wage changes from 2005 to 2006. Due to their sudden appearance in an otherwise stable environment, we take the 
variation in these wage changes across different gradeXstep combinations as plausibly exogenous. As such, we estimate the impact of wages on attrition from the public payroll using a difference-in-differences estimator:

$$
A_{i t}=\alpha+\beta w_{i t}+\delta^{\prime} x_{i t}+\text { gradeXstep } i+\eta_{t}+\epsilon_{i t}
$$

where $A_{i t}$ is an indicator of attrition from the payroll; $w_{i t}$ represents wages paid in the public sector in Ghana; $\eta_{t}$ is a time fixed-effect, gradeXstep $i$ is a dummy for which grade-step group an individual is in when they first enter the data; and $x_{i t}$ is a vector of controls for individual demographics, labor market conditions abroad, and other domestic policies. We will estimate equation (4) by instrumental variables, using wages that an individual would have received if never promoted as an instrument for actual wages. Formally, if log wages are defined as:

$$
w_{i t}=f_{t}\left(\text { grade }_{i t}, \text { step }_{i t}\right)
$$

where changes in $f_{t}(\cdot)$ embody policy changes to the public health sector wage schedule. Then we define an instrument $\hat{w}_{i t}$ as:

$$
\hat{w}_{i t}=f_{t}\left(\operatorname{grade}_{i 0}, \text { step }_{i 0}\right)
$$

where $\operatorname{grade}_{i 0}$ and $s t e p_{i 0}$ denote the grade and step of individual $i$ when we first observe them on the public payroll. Importantly, this instrument eliminates variation in wages that comes from promotions because this variation is likely to reflect ability and thus be endogenous. When combined with time fixed effects and group effects, the variation remaining is that caused by enactment of the new wage schedule.

\subsection{Potential Confounding Factors}

The sudden reforms of 2006 and otherwise stable wage environment create a reasonable natural experiment in which to measure the impact of wages. However, this identification strategy relies on the assumption that wage changes from 2005 to 2006 for different groups of workers can be taken as exogenous. We control for time and group effects, which remove the influence of time-variant factors that affect all groups of workers similarly and time-invariant differences across different groups. However, our identification could fail if the government of Ghana directed the largest wage increases to groups of workers based on characteristics correlated with attrition. As such we control for the demographic and job characteristics available in our data including age, gender, district of job placement, and department of job placement.

Aside from the wage reforms, other similarly-timed domestic policies also likely affected migration. In Ghana, several measures were taken with the goal of reducing migration of health workers. The Ghana College of Physicians and Surgeons opened in 2004, becoming the first medical specialist training school in Ghana. It is thought to have decreased migration of doctors who would have otherwise migrated for training purposes. Also during this time period, the 
Ministry of Health and the Nurses and Midwives Council collaborated with the service delivery agencies to enforce a bonding scheme for nurses. Under this program, publicly-trained nurses were required to complete a term of public service or pay a bond before they could be given verification by NMC to practice abroad. Other policies to reduce migration included a subsidized car loan scheme as well as increased availability of fellowships for continuing professional education.

Outside of Ghana, major policy changes also occurred, particularly in the UK. In 1999, the UK National Health Service adopted a Code of Practice limiting recruitment from developing countries. This policy strengthened considerably in subsequent years as the UK moved to limit not just the NHS, but also recruitment agencies working on behalf of the NHS. Meanwhile, wages and domestic supply of health workers in the UK were changing and could also coincide with the wage reforms that we are studying in Ghana. For both foreign and domestic policies, if they affect all health workers equally, then our identification will still be valid. However, if any policy disproportionally affects particular groups of health workers, then this could bias our results. Figure 6 demonstrates that this does not appear to be a problem with regard to changes in UK demand for foreign health workers. Overall inflows of health workers from the world into the UK have decreased dramatically, but the change has affected doctors and nurses similarly. In any case, we will demonstrate that our identification strategy is not affected by controlling for the impacts of both foreign and domestic policy changes.

Of course, unobservable factors could affect the validity of our identification strategy. For example, if wage increases are targeted at groups whose attrition rates are already decreasing, this will bias the estimates downward. This is an important issue that we address by controlling for group-specific time trends. Another possible concern relates to ability of the workers. While controlling for group effects at a fine level and removing promotions from our instrument should reduce bias generated by ability and positive selection, unobserved ability could still generate endogeneity. For example, our specification focuses on the contemporaneous effect of wages on attrition, but if individuals make migration decisions based on lifetime expected wages, then our instrument will systematically underestimate home wages for high ability individuals who expect to be promoted. Since migration likely selects on ability, this would induce correlation between our instrument and the error term. We expect that the magnitude of bias created by this type of endogeneity will be small because of how finely our groups are defined; however, we cannot rule out such a possibility.

\section{Data}

\subsection{Administrative Wage Data}

The main data source used in this study is individual-level payroll data obtained from the Controller and Accountant General's Directorate of the Government 
of Ghana. This data contains payroll records from 2003 to 2009 for each health worker classified under $\mathrm{MOH}$ paid by the central government including employees of the Ministry of Health, Ghana Health Service, Christian Health Association of Ghana (CHAG), the teaching hospitals, and $\mathrm{MOH}$ training institutions. This panel data provides individual-level observations over several years, and yields a rich picture of the health labor market in Ghana. Additionally, for each individual this data provides detailed information on employee grade (i.e. Senior Medical Officer, Chief Lab Technologist, etc.) and salary step for each individual. Information on age, gender (equals 1 if male), department (CHAG, GHS, Headquarters, etc.), and district of posting are also available.

We use health sector public wage schedules to map grade and step into a basic salary for each worker. As described above, a major part of the 20052006 salary changes hinged on the Additional Duty Hours Allowance. Thus, it is important to consider not just the basic salary but also the Additional Duty Hours Allowance for each worker. Since ADHA was allocated according to a fixed formula that depends on a worker's category and their base pay, the payroll data along with data on ADHA hours allotments from GHS allow us to estimate their ADHA earnings. From 2003-2005 the formula for total wages is:

$$
w_{i t}=\log \left(E_{i t}+\frac{E_{i t}}{160} \times 1.75 \times h_{g_{i t}}\right)
$$

where $E_{i t}$ is the basic salary of individual $i$ at time $t$ and $h_{g_{i t}}$ is the number of ADHA hours allotted to a worker in grade $g_{i t}$, which is the grade of worker $i$ at time $t$. From 2006-2009, we simply use the log of basic salary. Table 2 provides sample statistics. The first column describes potential migrants (defined below), which is our main sample. Real (measured at 2004) monthly wages for this group average 447 Ghana Cedis ${ }^{2}$.

As described above, our instrument for log wages will be log wages that would be earned by worker $i$ if he or she was never promoted. In particular, the instrument for a worker $i$ at time $t$ takes the value from the time $t$ wage schedule for a worker with the grade grade $_{i 0}$ and step step $_{i 0}$ where grade $_{i 0}$ and $s e_{i 0}$ are the grade and step of worker $i$ when he or she first enters the data. One complication with this definition is that from 2005 to 2006, the entire wage schedule changed from the Ghana Universal Salary Structure (GUSS) to the Health Salary Structure (HSS). As a result, the number of steps for a given grade changed in some instances. In these cases, the new step is approximated to reflect the same percentage progress up the grade. Formally, starting in 2006 an individual's 'first-observed step' within the HSS is defined as:

$$
\text { step }_{i 0}^{H S S}=\text { step }_{\text {lowest }}^{H S S}+\left(\text { step }_{i 0}^{G U S S}-\text { step }_{\text {lowest }}^{G U S S}\right) \times \frac{\text { totalsteps }_{i}^{H S S}}{\text { totalsteps }_{i}^{G U S S}}
$$

where $s t e p_{i 0}^{G U S S}$ is an individual's 'first-observed' step under the GUSS system; $s_{\text {step }}$ lowest is the entry-level step for individual $i$ 's grade and totalsteps refers to the total number of steps in $i$ 's grade under a particular salary schedule.

The payroll data is monthly but due to technical challenges does not cover all months prior to 2006. As a result, it is not possible to study attrition over

\footnotetext{
${ }^{2}$ About 500 USD.
} 
monthly intervals. Thus, we analyze the data at intervals approximating one year. To this end, we only use data from selected months: November 2003, July 2004, December 2005, December 2006, December 2007, December 2008, and July 2009. Since we use time fixed effects, the varying lengths of time between observations should not be an important issue.

\subsection{Measuring Attrition}

Individual records can be matched from year to year based on identifiers in the data. In particular we match records on first name, last name, gender, and date of birth ${ }^{3}$. We use these matched records over time to measure attrition of health workers from the payroll. In particular, if an individual is in the sample at time $t$ but never after time $t$, we say the individual attrited at time $t$. In this study, we usually interpret the impact of wages on attrition from the payroll as the impact of wages on migration. The two are not, of course, generally equivalent. Workers could potentially leave the public payroll for employers outside the dataset (i.e. the private sector or military hospitals), or they could retire from working in the health field. We emphasize migration, but we cannot explicitly separate migration from other forms of attrition in the data.

\subsection{Choosing the Sample}

Interpretation of the results depends heavily on what part of the sample we use because the data covers workers of all ages and occupations with widely varying skill sets, education requirements, and responsibilities. For older workers, retirement is a major consideration. In our data, the probability of remaining after 20-40 years of experience is still positive and decreasing. This indicates that a significant minority of health workers still remains and attrite from the public sector after long careers. Retirement is an obvious explanation. To focus on migration rather than retirement, we truncate our main sample to those 40 years of age and younger, though we will expand this scope when we investigate the impact of wages on workers on different ages.

We also split our sample based on whether workers' occupations allow them to be a 'potential migrants.' Classification as such was determined after conversations with administrators in the Ministry of Health and Ghana Health Service. The first column of Table 3 provides a list of all worker categories classified as potential migrants along with their prevalence in the 2003-2006 sample. As expected, nurses and physicians compose much of the 'potential migrant' sample, though there are also many medical assistants (nurse practitioners) and skilled allied health workers, such as laboratory and x-ray officers. The second column indicates those excluded from this group, mostly low-skilled workers (orderlies,

\footnotetext{
${ }^{3}$ Employee numbers are available in the data and in most circumstances would be ideal. However, the treatment of some cadres' employee numbers changed from 2005 to 2006. Given this re-definition of employee numbers comes at the same time as the natural experiment, we choose to use a consistent method of matching over all time periods. Since these demographic identifiers are nearly always unique, this method is preferred.
} 
watchmen, drivers, etc.), as well as clinical workers whose skills are in low demand in developed countries (midwives, community health nurses, etc.). Nurses in training are available in the database but excluded from both groups because they are in school and receive only small stipends. The second column of Table 2 shows that, as expected, the non-potential migrants have an attrition rate about half that of the potential migrants, and they are paid less than half as much. However, mean age (conditional on being younger than 40) and gender distribution are similar to our main sample: average age is around 32 and just over half of individuals are female.

Splitting the sample in this way provides two services. First, it again focuses analysis on categories of workers that were known to have high rates of migration during the sample period. This helps focus the analysis on a group where there are external reasons for believing that migration is a main cause of attrition. Second, it also provides the opportunity to test whether wages affect these two groups in similar or different ways. Since retirement and the private sector are open to both the potential migrants in our main sample and to those excluded from our main sample, if we observe similar effects of the wage changes on both groups, then this would indicate that we are observing the effect of wages on some other form of attrition rather than migration. However, if the wage reforms show no effect on attrition of non-migrants, then we are likely measuring the impact of wages on migration.

Aside from limiting the sample in reasonable ways, circumstantial evidence also indicates that the large scale attrition seen in the data can most plausibly be explained by migration. As Table 2 shows, in our data roughly 8 percent of all potential migrant health workers leave the public payroll each period. As we have already seen, this coincides with well-known large-scale migration of health workers from Ghana. So, migration is at least consistent with the attrition rates in our data. Additionally, other forms of exit seem implausible. Large-scale retirement for young workers seems unlikely. Due to central payment of not only GHS but also CHAG and others, our data cover the vast majority of all health workers in Ghana. Ghana $\mathrm{MOH}$ estimates that 81.9 percent of all healthworkers work in the institutions covered by our sample, with most of the remainder in the private for-profit sector or prison and military hospitals. Also, for many categories of potential migrant health workers, coverage of our data frequently surpasses 90 percent (Ministry of Health (2007)). Given the small proportion of health workers in for-profit and military medicine, these sectors' human resource usage would have to increase by about 40 percent per year to absorb all of the health workers leaving the public payroll. What data exists on the private sector is not consistent with this story. For example, the World Health Organization's National Health Accounts indicate that the private sector's share in health sector spending actually fell from 58.6 percent to 48.4 percent from 2000 to 2007 (World Health Organization (2010)). Thus, external evidence seems to indicate that attrition from the public payroll in our sample is more plausibly attributed to migration than to other causes. 


\subsection{Additional Data Sources}

The payroll data is supplemented by data from other sources. For inflation we use the GDP deflator from the World Bank's World Development Indicators. All values are reported in real 2004 Ghana Cedis. In 2004, the average exchange rate was USD 1.12 per Ghana Cedi. Foreign wages are drawn from the UK Annual Survey of Hours and Earnings. Individuals are matched to UK wages based on their cadre (doctor, professional nurse, etc.) at the SIC 4-digit level, when possible. Others are matched to SIC 3-digit and 2-digit codes when necessary. Necessarily, these data are not nearly as precisely measured as home wages because they are not individual specific. UK wages are changed into Ghana Cedis using PPP exchange rates from the Penn World Tables. As Table 1 shows, wages in the UK average 1121 Ghana Cedis per month at PPP rates. This is 2-3 times the purchasing power of the average domestic salary.

In addition to wages, other labor market factors in the UK likely affected migration during this time period, particularly adoption and strengthening of the NHS Code of Practice. We control for this using a measure of the openness of the UK to migrants from different professions: the log of the total number of new migrants to the UK for a particular profession in a given year from all source countries. We have this variable available from registration data in the UK with physicians from the UK General Medical Council, nurses from the UK Nurses and Midwives Council, and others (Art Therapists, Biomedical Scientists, Clinical Scientists, Dieticians, Occupational Therapists, Orthopists, Physiotherapists, Radiographers, and Audiologists) from the UK Health Professions Council. In our data, we also match Ghanaian dentists as physicians in the UK; medical assistants and anesthetist assistants as nurses; lab assistants and lab technical officers as clinical scientists; nutrition officers as dieticians; and x-ray officers as radiographers. For other categories, we code the variable as zero.

Two concurrent domestic policies affecting health worker migration are included in some specifications. The Ghana College of Physicians and Surgeons opened in 2004, becoming the first specialist training school in Ghana. It is thought to have decreased migration of doctors who would have otherwise migrated for training purposes. We measure this using enrollment in the Ghana College of Physicians and Surgeons, with data drawn from the Ghana College's newsletter as well as media reports. We include enrollment in the Ghana College interacted with a dummy for non-specialist doctors as a control. Also, during the sample period the Nurses and Midwives Council, in cooperation with GHS, began enforcing a public-sector service requirement for nurses. They began withholding certification from nurses who wished to migrate until they served

their bond period. We model this as a dummy that is one for nurses starting in 2006 and zero otherwise. 


\section{Results}

\subsection{Main Effects}

We estimate the instrumental variables regression of equation (2) with $\hat{w}_{i t}$ as an instrument for $w_{i t}$. Table 4 shows the results for this regression. Coefficients on wages are normalized so that they can be interpreted as the percentage point change in migration resulting from a 10 percent wage increase. Each column represents a different specification. First stage F-statistics are reported at the bottom of each column and indicate that a weak first stage should not be a problem. Column (1) of Table 4 shows the results for the 'potential migrants' sample with no covariates other than the time effects and gradeXstep effects. The coefficient is negative and statistically significant at the 1 percent level, indicating that the 'push' effect of wages outweighs any credit constraint effect. The coefficient of -1.59 indicates that a 10 percent wage increase would lead to just over one and a half percentage point decrease in attrition. This is fairly substantial relative to the average attrition rate of about 8 percent. Column (2) adds a full set of controls for UK wages, total migration to the UK by profession, the two concurrent domestic policies, gender, a quartic polynomial in age, a set of dummies for department of posting, a set of dummies for district of posting, and gradeXstep specific time trends. Controlling for these observables, the point estimate remains negative but decreases in magnitude while the standard errors increase. As a results, this effect loses statistical significance. So far, this provides suggestive but not conclusive evidence that changes in wages rather than other factors drive the results.

Contrast these results with the final two columns, which estimate the same equations on the sample of occupations that do not tend to migrate. With and without controls, the effect is positive, statistically insignificant, much smaller in magnitude, and precisely estimated. Thus, we have some suggestive evidence that higher wages decrease the probability of attrition for professions that do migrate but no evidence that such an effect exists for professions that do not tend to migrate. Since other interpretations of attrition such as retirement and moving to the private sector are available to both groups, it seems unlikely

that these drive the results. Migration appears to be more consistent with the evidence.

\subsection{Age Heterogeneity}

Cutting the sample into 5 -year increments by age provides additional insight. To this end, we estimate equation (2) on sub-samples of individuals age 20-25, $25-30$, etc. We include (previously excluded) individuals up to 65 years of age to get a wider view on the impact across different ages. Table 5 displays the coefficient on log wages for these different age groups, with columns denoting the different specifications described previously. For the main sample, the negative effect is clearly strongest among the young workers under age 35, though the small sample of 20-25 year-olds makes that estimate imprecise. Importantly, 
the effects for 25-35 year-olds remain both statistically and economically significant when including the full set of controls. While our results for the main sample were only suggestive, these results provide more definitive evidence that higher wages do in fact decrease attrition for the youngest workers. Finally, the effects on individuals age 35-55 show coefficients that are smaller in magnitude and statistically insignificant. The 55-65 year-old groups provide an interesting result, suggesting a sizable negative effect of wages on the retirement decision.

As before, the last two columns of Table 5 refer to those workers on payroll who are unlikely to migrate. Column (3) indicates that, for this sample, our inability to detect a relationship between wages and attrition is consistent across all age groups. The estimates are small in magnitude and statistically insignificant. When we add in the controls in column (4) the results remain similarly insignificant with one exception. Among the older workers 50-60, we find evidence of higher wages cutting attrition, likely due to postponed retirement. Altogether, these results tell a clear story. Higher wages for older workers cut attrition in both samples, but higher wages for younger workers only cut attrition among potential migrants. For older workers, higher wages can affect a reason for attrition that is common among all workers: retirement. But since the impact on younger workers rests only with one part of the sample, we infer that higher wages affect a form of attrition particular to this sub-sample: migration. Altogether, we take the results as evidence that higher wages decrease migration among young potential migrants while having no effect on mid-career workers and decreasing retirement for all late-career workers.

The effect among early and mid-career workers is consistent with the simplest model of migration that focuses on how increasing home wages reduces a push effect. It is perhaps not surprising that these effects diminish for older cohorts. In a life cycle model of migration, a fixed cost of migration finances the opportunity to receive higher annual wages. With fewer years remaining, older workers face a similar cost but lower benefits to migrating. Additionally, if individuals differ idiosyncratically in their preference for migration, the health workers that have chosen to remain in Ghana for several years may be a selected group that has such a low probability of migrating that marginal wage changes have no impact. Finally, ageing itself may be correlated with other factors (marriage, having children, building a home, etc.) that may make individuals very unlikely migrants, again causing wages to have no measurable impact on this very small probability. These explanations are all observationally equivalent in our data, but they provide ample explanation for the fact that the effect diminishes in older cohorts. In any case, it appears that these factors outweigh the impact of credit constraints, for in a model of credit constraints we would expect the youngest individuals to have low wealth and thus be credit constrained. Then, it would be these individuals for whom the 'push' effect would be most offset by a more relaxed credit constraint. Clearly, we do not observe this effect as dominant in this data. 


\section{Robustness}

\subsection{Political Economy and Average Causal Response}

In instrumental variables analysis, if treatment effects are heterogeneous across individuals then the estimated coefficient is a local area treatment effect (LATE) for those individuals who comply with treatment. In our context of variable intensity of treatment, the analogous concept is Average Causal Response (ACR). ACR measures a weighted average of LATE's, where the LATE's are expectations over the compliers who are moved above a particular treatment level by the instrument and weights give weight to treatment levels in proportion with the number of compliers (Angrist and Pischke (2009)). For our purposes, wage increases may be uncorrelated (given covariates) with the error term, but they may still be directed toward groups with high or low values for $\beta$, creating an ACR that may not be representative of the impact of wage increases on a random sample of potential migrants in Ghana. For example, the government may direct wage increases toward individuals with the lowest (most negative) $\beta$ 's to reduce migration by the largest amount. To the extent that in future action the government will direct wage increases in a similar manner, then the effect measured here is actually more useful than the impact on a random sample of health workers. However, exploring this more closely will help with interpreting the results.

In an ideal world we would test for heterogeneity of $\beta$ by extending the model for this case explicitly to estimate $\beta_{g s}$ specific to each group:

$$
A_{i t}=\alpha+\beta_{g s} w_{i t}+\delta^{\prime} x_{i t}+\text { gradeXstep }_{i}+\eta_{t}+\epsilon_{i t}(3)
$$

Then, we could estimate $\hat{\beta}_{g s}$ and test for the impact of $\hat{\beta}_{g s}$ on wage increases:

$$
\hat{w}_{g s}^{2006}-\hat{w}_{g s}^{2005}=\alpha+\gamma * \hat{\beta}_{g s}+\delta * X_{g s}^{2003}+\epsilon_{g s}
$$

However, due to the fact that our instrument only varies across groups and time, estimation of the first equation is not identified. We consider the following equation instead:

$$
A_{i t}=\alpha+\beta_{g s} \hat{w}_{i t}+\delta^{\prime} x_{i t}+\text { gradeXstep }_{i}+\epsilon_{i t}
$$

where there is no time fixed effect and for simplicity, we use the reduced form of regressing directly on the instrument. Without the time fixed effect, the equation is identified, but the estimates of $\beta_{g s}$ will be biased due to correlation with the error term. Suppose there are no covariates (including foreign wages), then we can express the true model in equation (5) in differences from group means:

$$
\Delta A_{i t}=\beta_{g s} \Delta \hat{w}_{i t}+\Delta \eta_{t}+\Delta \epsilon_{i t}
$$

where the $\Delta$ indicates difference from gradeXstep mean. Then, if we estimate $\hat{\beta}_{g s}$ without the time fixed effect, we can express the bias in this manner: 


$$
\hat{\beta}_{g s}=\frac{\operatorname{Cov}\left(\Delta A_{i t}, \Delta \hat{w}_{i t}\right)}{\operatorname{Var}\left(\hat{w}_{i t}\right)}=\beta_{g s}+\frac{\operatorname{Cov}\left(\Delta \eta_{t}, \Delta \hat{w}_{i t}\right)}{\operatorname{Var}\left(\hat{w}_{i t}\right)}
$$

Importantly, if the correlation between wages and the time-effect component of the error is constant across groups, then the bias is likewise the same for all groups. This is exactly what occurred during the pre-2006 period. All groups received common percentage raises and thus have the same correlation with the common time fixed-effect. Thus:

$$
\hat{\beta}_{g s}=\beta_{g s}+\psi
$$

from 2003-2005. This common bias is absorbed by the constant in equation (4), giving us a consistent estimate of $\gamma$, i.e. the extent to which wage increases are targeted at groups based upon their responsiveness to wages.

We estimate the $\beta_{g s}$ parameters from two different models, with $\hat{\beta}_{g s}^{\text {short }}$ cor-

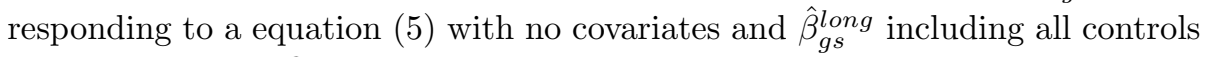
except group-specific time trends, which we exclude due to only having two time periods before 2006. Table 6 provides the final results of regressing 2005-2006

$\log$ wage changes on the estimated $\hat{\beta}_{g s}$ parameters. Columns (1) and (2) find negative coefficients of -0.0045 and -0.0051 , both of which are statistically significant, indicating that wage increases may have been aimed toward groups that were more responsive to wage increases (more negative $\beta_{g s}$ ). When we include controls for average age and proportion of females in columns (3) and (4), these results remain very similar.

These results suggest that the government directed raises at those groups of workers who were most responsive to such increases. Thus, our results likely measure a treatment effect of greater magnitude than what would be measured if wages were randomly assigned. In this sense, our results are an upper bound for the effect of wages on attrition. However, it seems likely that future pay increases will also be directed toward those categories of workers who are most responsive to salary changes. In this context, we measure an average causal response that is relevant to policymakers who are choosing not only the level but also the distribution of pay increases.

\subsection{Sample Selection and Hazard Models}

Due to the nature of the data available, the sample available at any time period $t$ is necessarily the sample of those who have chosen to remain. This selected sample is not random, and it is well-known that selected samples can create biased estimation if the unobservables determining selection are correlated with the regressors (Heckman 1979, Vella 1998). If our instrument is uncorrelated with these unobservables, then this source of bias should not be present. Given our natural experiment approach to instrument selection, there is reason to be confident that sample selection bias does not affect our results significantly. However, one way to check for the robustness of this assumption is to directly estimate hazard models. The dependent variable of interest in our study is the probability of leaving the sample conditional on remaining in the sample until that time, i.e. a hazard rate. There is a large class of hazard and survival 
models designed for this type of dependent variable that explicitly model the tendency of individuals to leave the sample (or more traditionally, die).

One type of model explicitly models the hazard itself. We adopt the commonly used Cox Proportional Hazards model, where the hazard is assumed to be:

$$
\lambda\left(\tau \mid z_{i t} ; \theta\right)=\lambda_{0}(\tau) \exp \left(\beta_{0}+\beta_{1} w_{i t}^{*}-\beta_{2} \hat{w}_{i t}+\delta^{\prime} x_{i t}+\text { gradeX }_{\text {step }}+\eta_{t}\right)
$$

where $z_{i t}$ is the data, $\theta$ is all of the parameters, and $\tau$ is the length of time since an individual began working for the Ghanaian government. Importantly, the duration dependence, $\lambda_{0}(\tau)$, that allows the probability of migrating vary over the course of a career does not need to be parameterized. Only the impact of the covariates needs to be parameterized (here as an exponential). Given this assumed hazard form, a quasi-likelihood function can be formed so that the parameters can be estimated consistently without estimating $\lambda_{0}(\tau)$. Also, we use the instrument $\hat{w}$ rather than actual wages in an attempt to preserve our natural experiment. Given strong correlation of the instrument with wages, this approximation should be quite good.

We estimate this model by quasi-maximum likelihood and display the results in Table 7. The coefficient on the wage instrument is negative and statistically significant for both models. ${ }^{4}$ The coefficients themselves have little meaning; as such, hazard ratios are often reported. Here we report the ratio of the hazard rate (probability of migrating) with a 10 percent wage increase relative to the hazard rate without the increase. The resulting hazard ratio is 0.81 with no controls and 0.70 with the full set of controls, indicating that a ten percent wage increase would decrease the hazard of attrition by 19 to 30 percent. This is actually slightly stronger than our previous result, where a 10 percent wage increase decreased a mean 8 percentage point migration rate by 0.9 to 1.6 percentage points, i.e. by 10 to 20 percent.

\section{Conclusion}

This paper measures the impact of home wages on attrition of skilled health professionals from the public sector in Ghana by exploiting variation in wages caused by a policy-induced natural experiment. We find that a 10 percent wage increase reduces the annual attrition rate by 0.9 to 1.6 percentage points. This effect is concentrated solely among young workers age 20-35 who come from professions that tend to migrate. We take this as evidence that the effect of wages on attrition from the public sector mainly runs through migration. Unlike previous attempts at measuring the impact of home wages on migration through macro data or parametric selection models, we find this negative effect of home wages on migration to be economically significant and robust to specification. These results support the most basic economic models of migration in which individuals choose to migrate based on wage differentials between home and

\footnotetext{
${ }^{4}$ Caution should be taken in inference, as the standard errors cannot be clustered
} 
foreign countries. These results run counter to expectations that the impact of marginal wage changes may be small when wage gaps are very large or that higher home wages might relax credit constraints causing more migration.

As with all experiments, natural or designed, high internal validity does not guarantee external validity of the results. Context is important. The individuals in this study are highly-skilled health professionals who tend to migrate permanently with their families. The results will not necessarily apply to low-skilled or low income individuals who may face tighter credit constraints. However, the sample studied here is both under-studied and of policy significance. While our use of attrition from public payroll rather than an explicit measure of migration creates uncertainty about whether we are measuring other forms of attrition, it does allow us to approach the phenomenon of permanent migration on the individual level with a broad sample. In doing so, we find evidence for a vital element of migration theory in a sample characterized by long-term, permanent migration.

The migration behavior of skilled health workers is of particular policy importance. Health policy and strengthening health systems in particular have gained great notoriety recently. In this context, migration of skilled health professionals away from developing countries has been widely debated. To many, it is a notorious 'brain drain' of needed health workers from places where skilled health professionals are already scarce (e.g. Chen and Boufford (2005)). As a result, many paths have been taken toward reducing such migration. For example, the UK National Health Service's has voluntarily imposed restrictions on foreign recruitment via its Code of Conduct, and this idea has been taken up recently by the World Health Assembly. To others, restrictions on migration are seen as violating human rights of migrants, ignoring more important problems of health worker performance and urban-rural distribution, or driven by recouping misguided education subsidies (e.g. Clemens (2009)). While important, deciding this debate is certainly out of reach for this article.

However, we do demonstrate that health workers can be retained, not just by restrictions on leaving but also by rewards for staying. If policymakers in developing countries desire to retain more health workers, as most do, then our results indicate that increasing salaries is one effective option. If policymakers in developed countries desire to redistribute health workers, subsidizing health worker salaries in sending countries is one means to this end that does not involve restrictions on the movement of individuals. Our results also indicate that migration of health workers should be an important consideration as policymakers in developing countries contemplate public sector wage reforms. As Ghana considers transitioning all public workers to a Single Spine Salary Structure, future policy research needs to more closely examine how such a change in public sector compensation would affect migration of health workers.

Of course, salaries for health workers are expensive, and other factors enter the cost-benefit calculus. For example, when dealing with fairly rigid public pay schedules, raising wages for health workers can sometimes lead to calls for wage increases in other sectors of the public payroll. While a complete costbenefit analysis is beyond the scope of this paper, we do make progress toward 
measuring the cost-effectiveness of using higher salaries to reduce attrition of skilled health workers. This opens the way to compare salary increases with other policy options. 


\section{References}

[1] Angelucci, M. (2004) 'Aid and Migration: An Analysis of the Impact of Progresa on the Timing and Size of Labour Migration.' IZA Discussion Paper No. 1187.

[2] Angrist, J. and J.S. Pischke (2009) Mostly Harmless Econometrics: An Empiricist's Companion. Princeton University Press, Princeton.

[3] Bhargava, A. and F. Docquier. (2007) 'A New Panel Data Set on Physicians' Emigration Rates (1991-2004).'

[4] Bhargava, A. and F. Docquier. (2008) 'HIV prevalence and migration of healthcare staff in Africa.' World Bank Economic Review, 22.

[5] Borjas, G. (1987) 'Self-Selection and the Earnings of Immigrants' American Economic Review, 77(4).

[6] Burdett, K. and D. Mortensen. (1998) 'Wage Differentials, Employer Size, and Unemployment.' International Economic Review, 39(2).

[7] Chen, L. and J.I. Boufford (2005) 'Fatal Flows: Doctors on the Move' New England Journal of Medicine, 353(17).

[8] Clark, X., Hatton, T. J., and Williamson, J. G. (2007) 'Explaining US immigration, 1971-1998.' Review of Economics and Statistics, 28.

[9] Clemens, M. (2007) 'Do Visas Kill: Health Effects of African Health Professional Emigration.' Center for Global Development Working Paper 114.

[10] Clemens, M. (2009) 'Skill Flow: A Fundamental Reconsideration of SkilledWorker Mobility and Development.' Center for Global Development Working Paper 180.

[11] Dovlo, D. and F. Nyonator (1999) 'Migration of Graduates of the University of Ghana Medical School: A Preliminary Rapid Appraisal.' Human Resources for Health Development Journal, 3(1).

[12] Gibson, J. and D. McKenzie (2010) 'The Microeconomic Determinants of Emigration and Return Migration of the Best and Brightest: Evidence from the Pacific.' Journal of Development Economics, forthcoming.

[13] Hanson, G. (2008) 'International Migration and Development.' Commission on Growth and Development, Working Paper No. 42.

[14] Heckman, J. (1979) 'Sample Selection Bias as a Specification Error' Econometrica, 47.

[15] Lopez, R. and M. Schiff (1998) 'Migration and the Skill Composition of the Labour Force: The Impact of Trade Liberalization in LDCs.' The Canadian Journal of Economics, 31(2). 
[16] Mayda, A.M. (2008) "International migration: A panel data analysis of the determinants of bilateral flows" Journal of Population Economics, forthcoming.

[17] Ministry of Health (2007) 'Human Resource Strategies and Policies for the Health Sector: 2007-2011.'

[18] Okeke, E. (2009) 'An Empirical Investigation of Why Doctors Migrate and Women Fail to Go For Screening.' Unpublished dissertation, University of Michigan.

[19] Pedersen, P. J., M. Pytlikova and N. Smith (2004) 'Selection or network effects? Migration flows into 27 OECD countries, 1990-2000.' IZA Discussion Paper 1104.

[20] Vella, F. (1998) 'Estimating Models with Sample Selection Bias: A Survey' Journal of Human Resources, 33(1).

[21] Vujicic, M., et. al. (2004) 'The Role of Wages in the Migration of Health Care Professionals From Developing Countries' Human Resources for Health, $2(3)$.

[22] World Health Organization (2010) World Health Statistics 2010 WHO Press, Geneva.

[23] Yang, D. (2006) 'Why Do Migrants Return to Poor Countries? Evidence from Philippine Migrants' Responses to Exchange Rate Shocks' Review of Economics and Statistics, 88(4).

[24] Yang, D. and H. Choi (2007) 'Are Remittances Insurance: Evidence from Rainfall Shocks in the Philippines.' World Bank Economic Review, 21. 
Table 1: Destinations of Migrant Health Workers from Ghana

\begin{tabular}{l|c|c}
\hline \hline Destination & Nurses & Physicians \\
\hline \hline UK & $71 \%$ & $56 \%$ \\
US & $22 \%$ & $35 \%$ \\
South Africa & - & $6 \%$ \\
Canada & $3 \%$ & $1 \%$ \\
Australia & $2 \%$ & - \\
Other & $2 \%$ & $2 \%$ \\
\hline \hline Source: & Ghana Nurses and Midwives Council & Dovlo and Nyonator (1999) \\
\hline
\end{tabular}

Table 2: Sample Statistics

\begin{tabular}{l|c|c}
\hline \hline Sample & Potential Migrants & Others \\
\hline Attrition & 0.08 & 0.036 \\
& $(0.27)$ & $(0.19)$ \\
Real Ghana Wage & 447 & 179 \\
& $(239)$ & $(93)$ \\
Real UK Wage & 1133 & 582 \\
& $(774)$ & $(315)$ \\
Age & 32 & 32 \\
& $(4.3)$ & $(4.9)$ \\
Gender & 0.48 & 0.42 \\
& $(0.5)$ & $(0.49)$ \\
Nursebonding & 0.29 & 0 \\
& $(0.46)$ & $(0)$ \\
COPS & 22.2 & 0 \\
& $(46.2)$ & $(0)$ \\
Log UK Migrants & 6.7 & 0.1 \\
& $(3.7)$ & $(0.9)$ \\
\hline N & 22,117 & 54,900 \\
\hline \hline \multicolumn{2}{l}{ Source: Administrative payroll data. Standard deviations are in parentheses. } \\
The sample includes only individuals under age 40. \\
\hline \multicolumn{2}{c}{}
\end{tabular}


Table 3: Defining Potential Migrants

\begin{tabular}{|c|c|c|c|}
\hline Potential Migrants & & Others & \\
\hline Worker Category & $\begin{array}{c}\text { Number of Observations } \\
(2003-2006)\end{array}$ & Worker Category & $\begin{array}{c}\text { Number of Observations } \\
(2003-2006)\end{array}$ \\
\hline PROFESSIONAL NURSE & 25,761 & ORDERLIES & 18,138 \\
\hline MEDICAL OFFICER & 3,648 & COMMUNITY HEALTH NURSE & 16,149 \\
\hline MEDICAL ASSISTANTS & 1,773 & HEALTH/WARD ASSISTANT & 11,941 \\
\hline TECHNICAL OFFICER & 940 & MIDWIVES & 8,724 \\
\hline TECHNICAL OFFICER (LAB) & 858 & ENROLLED NURSES & 7,582 \\
\hline SPECIALIST & 805 & WATCHMEN & 3,413 \\
\hline MEDICAL OFFICER - HOUSEMAN & 790 & ACCOUNTS OFFICERS & 3,057 \\
\hline BIOMEDICAL SCIENTIST & 669 & DRIVERS & 2,836 \\
\hline HEALTH SERVICE ADMINISTRATOR & 538 & ARTISANS & 2,733 \\
\hline ANESTHETIST ASSISTANT & 511 & PHARMACY TECHNICIANS & 2,420 \\
\hline TECHNICAL OFFICER (XRAY) & 488 & BIOSTATISTICS ASSISTANTS & 2,174 \\
\hline TECHNICAL OFFICER (NUTRITION) & 482 & $\begin{array}{l}\text { FIELD TECHNICIANS } \\
\text { TEN }\end{array}$ & 2,154 \\
\hline FACILITY/DISTRICT DIRECTOR & 134 & LABOURERS & 1,940 \\
\hline HEALTH RESEARCH OFFICER & 117 & TYPISTS & 1,887 \\
\hline HEALTH EDUCATORS & 109 & ACCOUNTANTS & 1,697 \\
\hline PHYSIOTHERAPISTS & 106 & DISPENSING ASSISTANTS & 1,595 \\
\hline TECHNICAL OFFICER (ORTHOPEDIC) & 102 & KITCHEN ASSISTANTS & 1,588 \\
\hline PHYSIOTHERAPY ASSISTANT & 98 & SCAVENGERS & 1,588 \\
\hline DENTAL SURGEON & 96 & TECHNICAL OFFICER (CDC) & 1,511 \\
\hline MINISTRY-LEVEL DIRECTOR & 94 & STOREKEEPERS & 1,417 \\
\hline OCCUP. THERAPY ASSISTANT & 89 & CONSERVANCY LABOURERS & 1,407 \\
\hline RADIOGRAPHERS & 75 & MEDICAL RECORD ASSIST & 1,396 \\
\hline HEALTH PLANNERS & 64 & TECHNICAL OFFICER (BIOSTATS) & 1,315 \\
\hline OPTOMETRIST & 58 & PHARMACISTS & 1,099 \\
\hline DENTAL TECHNOLOGISTS & 49 & SECURITY GUARDS & 1,014 \\
\hline NURSING TUTOR & 30 & LABORATORY ASSISTANTS & 899 \\
\hline HEALTH EDUCATION OFFICER & 28 & WASHMEN/IRONERS & 868 \\
\hline OCCUPATIONAL THERAPISTS & 4 & STENOGRAPHERS & 856 \\
\hline
\end{tabular}


Table 4: Main Effects

\begin{tabular}{|c|c|c|c|c|}
\hline & (1) & $(2)$ & $(3)$ & (4) \\
\hline Sample & Potential Migrants & Potential Migrants & Others & Others \\
\hline Dependent Variable & Attrition & Attrition & Attrition & Attrition \\
\hline Log Ghana Wage & $\begin{array}{c}-1.59 * * * \\
(0.60)\end{array}$ & $\begin{array}{l}-0.89 \\
(0.91)\end{array}$ & $\begin{array}{c}0.12 \\
(0.16)\end{array}$ & $\begin{array}{c}0.33 \\
(0.36)\end{array}$ \\
\hline Log UK Wage & - & $\begin{array}{l}-0.14 \\
(0.16)\end{array}$ & - & $\begin{array}{l}-0.06 \\
(0.05)\end{array}$ \\
\hline Log UK Migrants & - & $\begin{array}{l}-0.0028 \\
(0.0034)\end{array}$ & - & $\begin{array}{c}0.000 \\
(0.001)\end{array}$ \\
\hline Nursebonding & - & $\begin{array}{c}0.12^{* * *} \\
(0.03)\end{array}$ & - & - \\
\hline COPS & - & $\begin{array}{c}0.00037^{* *} \\
(0.00017)\end{array}$ & - & - \\
\hline Gender & - & $\begin{array}{c}-0.030 * * * \\
(0.005)\end{array}$ & $\mathrm{NO}$ & $\begin{array}{c}0.012^{* * *} \\
(0.003)\end{array}$ \\
\hline Age Quartic & $\mathrm{NO}$ & YES & YES & YES \\
\hline Time Fixed Effects & YES & YES & YES & YES \\
\hline GradeXStep Effects & YES & YES & $\mathrm{NO}$ & YES \\
\hline Department Dummies & $\mathrm{NO}$ & YES & NO & YES \\
\hline District Dummmies & $\mathrm{NO}$ & YES & $\mathrm{NO}$ & YES \\
\hline GradeXStep Specific Time Trends & $\mathrm{NO}$ & YES & NO & YES \\
\hline $\mathrm{N}$ & 21,378 & 21,347 & 51,729 & 51,543 \\
\hline Number of Clusters & 329 & 327 & 971 & 967 \\
\hline First Stage F & 69 & 45 & 2561 & 400 \\
\hline
\end{tabular}


Table 5: Effects by Age Group

\begin{tabular}{|c|c|c|c|c|}
\hline & $(1)$ & $(2)$ & $(3)$ & $(4)$ \\
\hline Sample & Potential Migrants & Potential Migrants & Others & Others \\
\hline $20-25$ & $\begin{array}{c}-6.20^{* * *} \\
(1.28)\end{array}$ & $\begin{array}{c}7.20 \\
(20.12)\end{array}$ & $\begin{array}{l}-0.30 \\
(0.62)\end{array}$ & $\begin{array}{l}-1.19 \\
(2.87)\end{array}$ \\
\hline $25-30$ & $\begin{array}{c}-1.77 * * * \\
(-0.60)\end{array}$ & $\begin{array}{c}-1.78^{* *} \\
(0.72)\end{array}$ & $\begin{array}{c}0.01 \\
(0.32)\end{array}$ & $\begin{array}{c}0.29 \\
(0.76)\end{array}$ \\
\hline $30-35$ & $\begin{array}{c}-2.58 * * * \\
(0.55)\end{array}$ & $\begin{array}{c}-2.27^{* *} \\
(1.11)\end{array}$ & $\begin{array}{c}0.34 \\
(0.31)\end{array}$ & $\begin{array}{c}0.26 \\
(0.61)\end{array}$ \\
\hline $35-40$ & $\begin{array}{c}0.66 \\
(0.73)\end{array}$ & $\begin{array}{c}1.72 \\
(1.10)\end{array}$ & $\begin{array}{c}0.14 \\
(0.24)\end{array}$ & $\begin{array}{c}0.57 \\
(0.57)\end{array}$ \\
\hline $40-45$ & $\begin{array}{l}-0.39 \\
(0.80)\end{array}$ & $\begin{array}{l}-0.63 \\
(1.05)\end{array}$ & $\begin{array}{c}0.00 \\
(0.23)\end{array}$ & $\begin{array}{l}-0.05 \\
(0.51)\end{array}$ \\
\hline $45-50$ & $\begin{array}{l}-0.10 \\
(0.53)\end{array}$ & $\begin{array}{l}-0.81 \\
(0.66)\end{array}$ & $\begin{array}{l}-0.00 \\
(0.15)\end{array}$ & $\begin{array}{l}-0.25 \\
(0.31)\end{array}$ \\
\hline $50-55$ & $\begin{array}{l}-0.74 \\
(0.69)\end{array}$ & $\begin{array}{l}-0.59 \\
(0.76)\end{array}$ & $\begin{array}{l}-0.13 \\
(0.15)\end{array}$ & $\begin{array}{c}-0.74^{* *} \\
(0.35)\end{array}$ \\
\hline $55-60$ & $\begin{array}{c}0.50 \\
(1.74)\end{array}$ & $\begin{array}{c}-2.83^{* *} \\
(1.38)\end{array}$ & $\begin{array}{c}0.04 \\
(0.59)\end{array}$ & $\begin{array}{c}-1.06^{* * *} \\
(0.53)\end{array}$ \\
\hline $60-65$ & $\begin{array}{l}-0.80 \\
(5.85) \\
\end{array}$ & $\begin{array}{l}-2.78 \\
(5.62) \\
\end{array}$ & $\begin{array}{c}3.47 \\
(3.00) \\
\end{array}$ & $\begin{array}{c}6.79 \\
(6.00)\end{array}$ \\
\hline Controls & $\mathrm{NO}$ & YES & $\mathrm{NO}$ & YES \\
\hline \multicolumn{5}{|c|}{$\begin{array}{l}\text { Statistical significance at the } 1,5 \text {, and } 10 \text { percent levels is denoted by }{ }^{* * *},{ }^{* *} \text {, and }{ }^{*} \text { respectively. } \\
\text { Standard errors are clustered at the gradeXstep level } \\
\text { Coefficients of a regression of attrition on log Ghana wage reported. }\end{array}$} \\
\hline
\end{tabular}


Table 6: Testing ACR

\begin{tabular}{|c|c|c|c|c|}
\hline Dependent Variable: & $\begin{array}{c}\Delta \text { Log Wages } \\
(1)\end{array}$ & $\begin{array}{c}\Delta \text { Log Wages } \\
(2)\end{array}$ & $\begin{array}{c}\Delta \text { Log Wages } \\
(3)\end{array}$ & $\begin{array}{c}\Delta \text { Log Wages } \\
(4)\end{array}$ \\
\hline$\hat{\beta}_{g s}^{\text {short }}$ & $\begin{array}{c}-0.0045^{* * *} \\
(0.0013)\end{array}$ & - & $\begin{array}{c}-0.0056^{* * * *} \\
(0.0014)\end{array}$ & - \\
\hline$\hat{\beta}_{g s}^{l o n g}$ & - & $\begin{array}{c}-0.0051^{* * *} \\
(0.0011)\end{array}$ & - & $\begin{array}{c}-0.0057^{* * *} \\
(0.0011)\end{array}$ \\
\hline Mean Age 2003 & - & - & $\begin{array}{c}0.0007^{* *} \\
(0.0003)\end{array}$ & $\begin{array}{c}0.0006 * * \\
(0.0003)\end{array}$ \\
\hline Proportion Female 2003 & - & - & $\begin{array}{l}0.008^{*} \\
(0.005)\end{array}$ & $\begin{array}{c}0.006 \\
(0.004)\end{array}$ \\
\hline $\begin{array}{l}\mathrm{N} \\
\text { R-Squared }\end{array}$ & 104 & $\begin{array}{c}162 \\
0.113\end{array}$ & $\begin{array}{c}104 \\
0.129\end{array}$ & $\begin{array}{c}162 \\
0.161\end{array}$ \\
\hline
\end{tabular}


Table 7: Cox PH Model

\begin{tabular}{|c|c|c|}
\hline & $(1)$ & $(2)$ \\
\hline Hazard Ratio & 0.81 & 0.70 \\
\hline Instrument for Log Ghana Wage & $\begin{array}{c}-21.0^{* * *} \\
(4.5)\end{array}$ & $\begin{array}{c}-35.1^{* * *} \\
(8.1)\end{array}$ \\
\hline Log UK Wage & - & $\begin{array}{c}-6.5^{* * *} \\
(1.4)\end{array}$ \\
\hline Log UK Migrants & - & $\begin{array}{l}-0.04 \\
(0.04)\end{array}$ \\
\hline Nursebonding & - & $\begin{array}{c}2.0^{* * *} \\
(0.4)\end{array}$ \\
\hline COPS & - & $\begin{array}{c}0.0039 \\
(0.0031)\end{array}$ \\
\hline Gender & - & $\begin{array}{c}-0.30^{* * *} \\
(0.08)\end{array}$ \\
\hline Age Quartic & NO & YES \\
\hline Time Fixed Effects & YES & YES \\
\hline GradeXStep Effects & YES & YES \\
\hline Department Dummies & NO & YES \\
\hline District Dummmies & NO & YES \\
\hline GradeXStep Specific Time Trends & $\mathrm{NO}$ & YES \\
\hline $\mathrm{N}$ & 14,685 & 14,669 \\
\hline
\end{tabular}




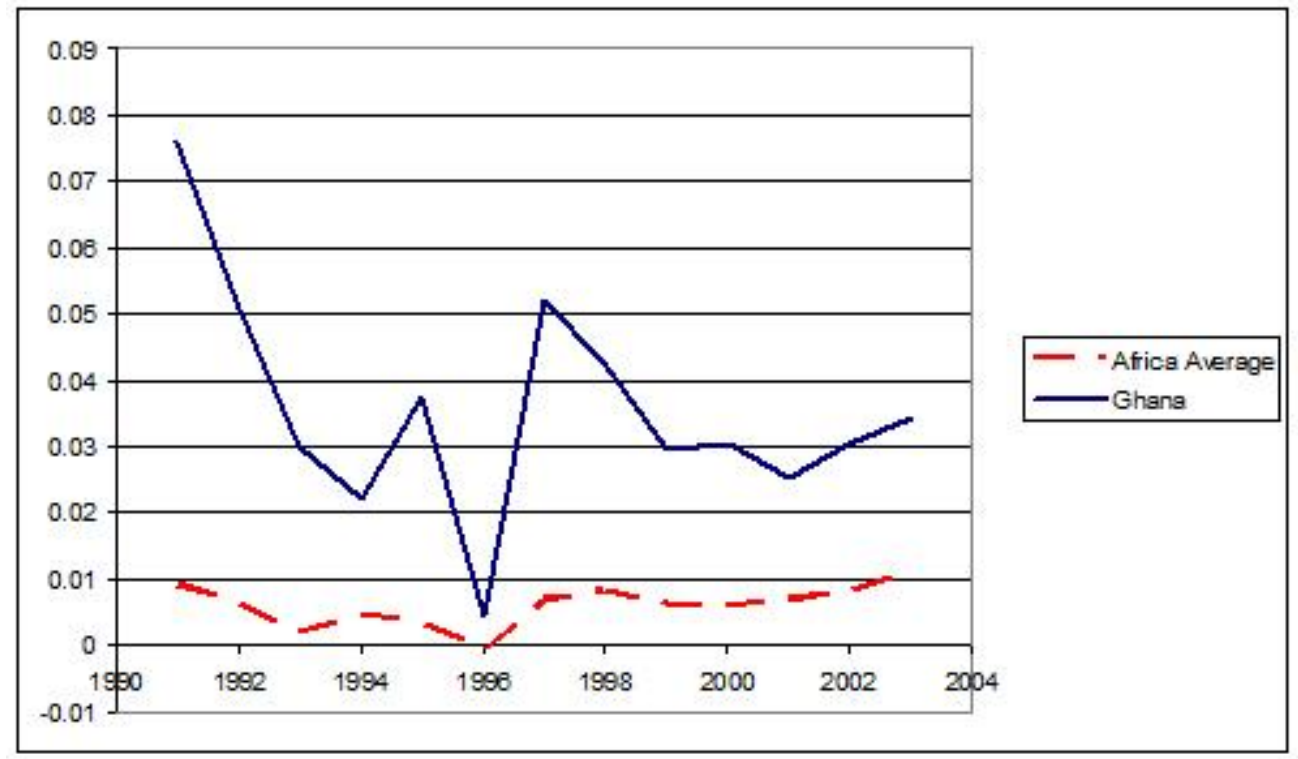

Figure 1: Historical Migration of Physicians from Ghana

Source: Bhargava and Docquier (2007); the data have been converted into flows

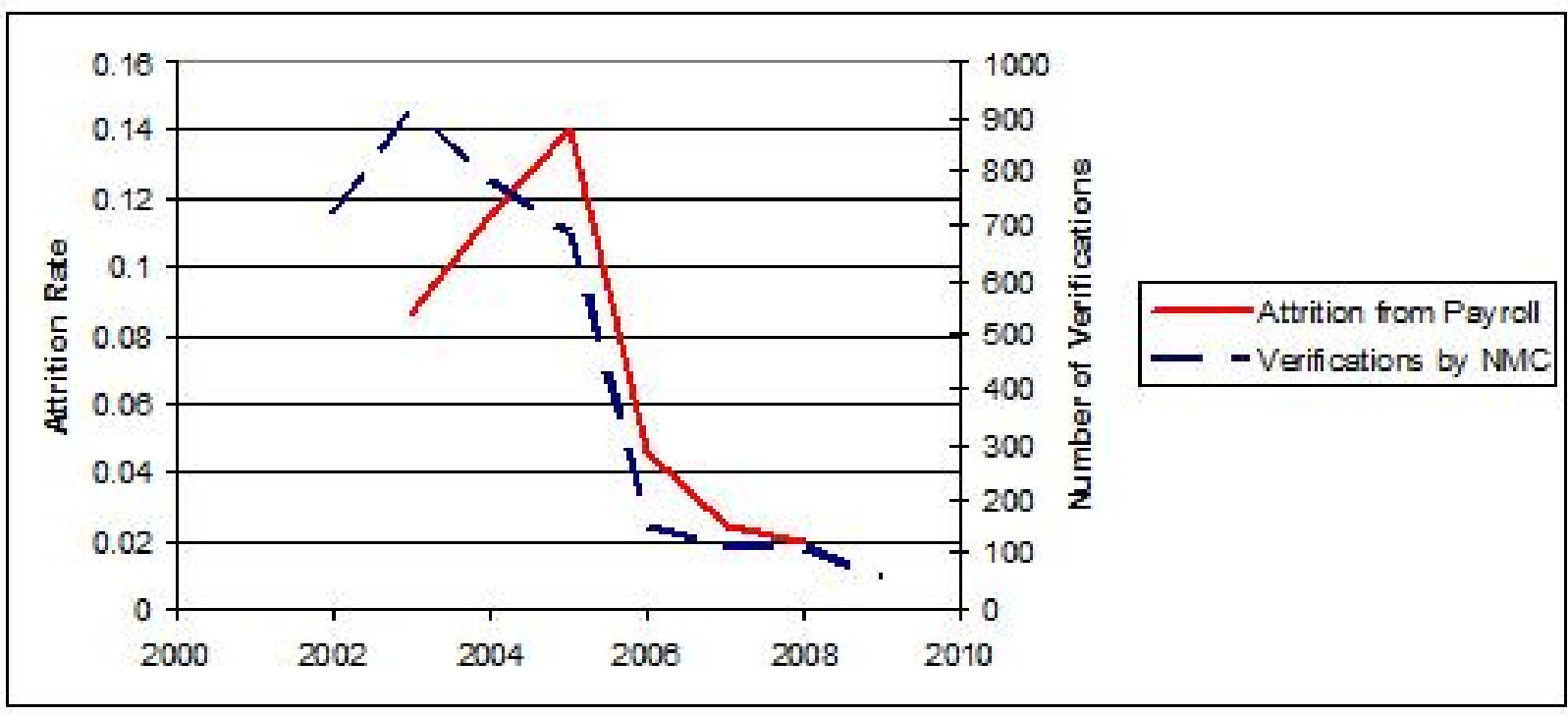

Figure 2: Migration and Attrition of Nurses from Ghana Sources: Nurses and Midwives Council; IPPD Payroll Database 


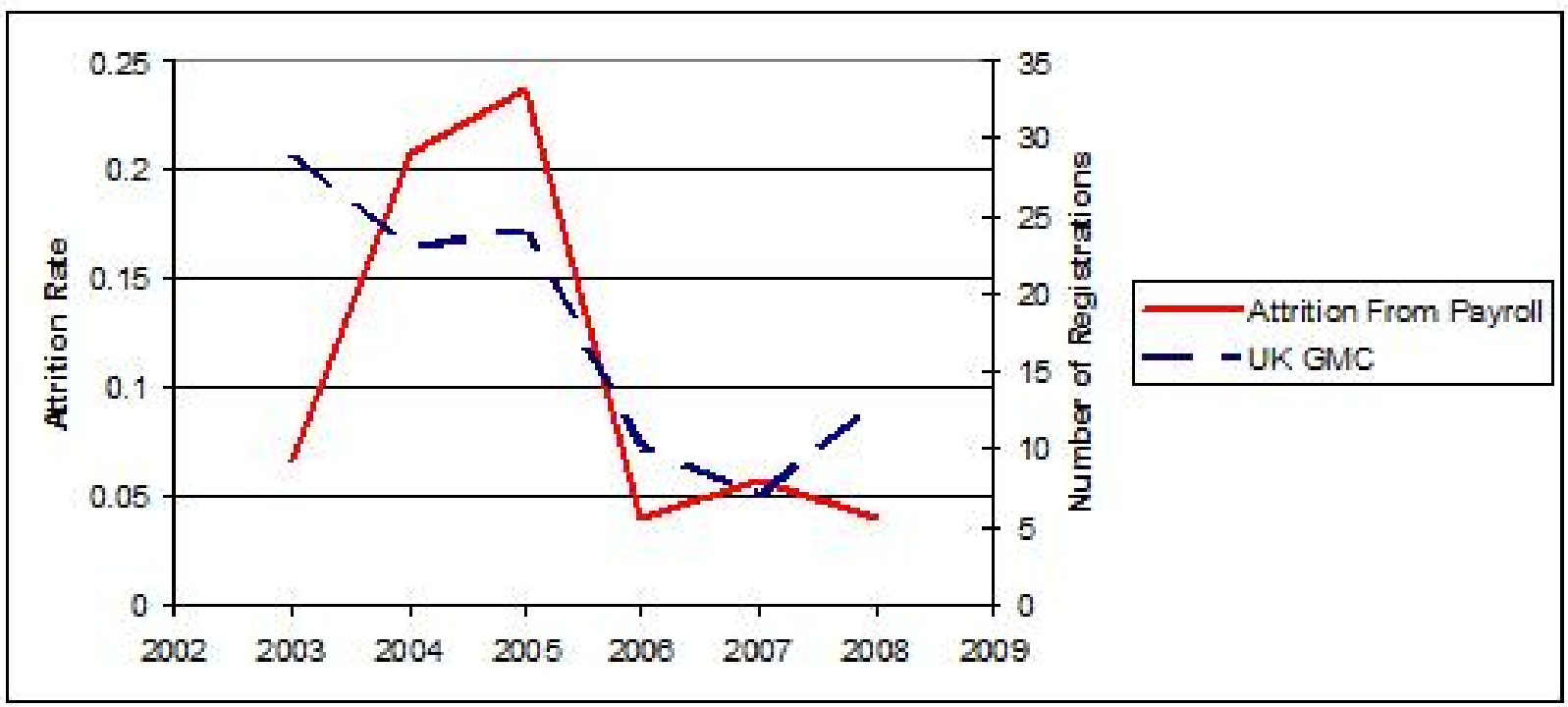

Figure 3: Migration and Attrition of Physicians from Ghana Sources: UK General Medical Council; IPPD Payroll Database

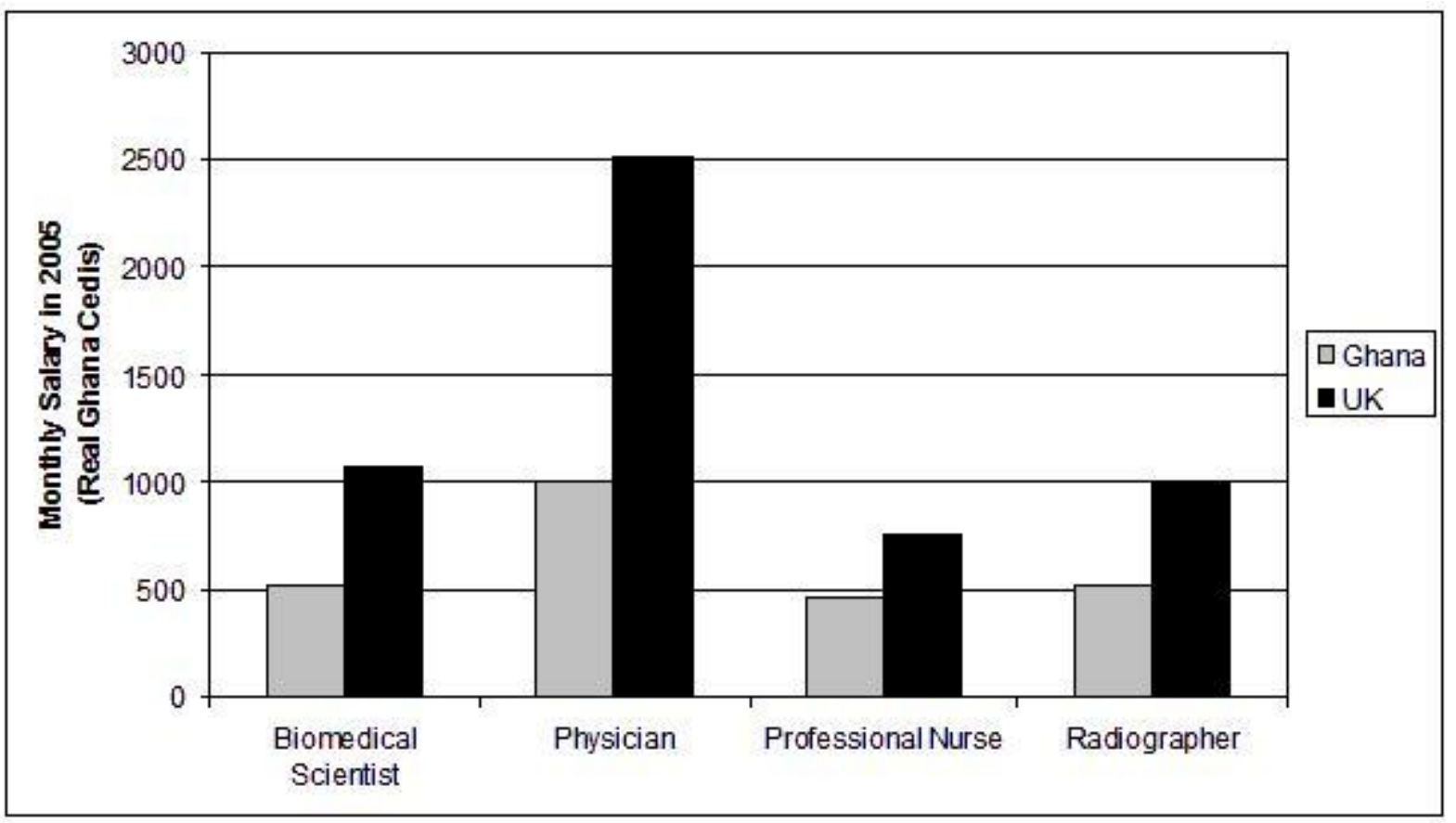

Figure 4: Salaries of Health Workers in Ghana and the UK Source: IPPD Database; UK Annual Survey of Hours and Earnings; UK figures are PPP 




Figure 5: Wages for Health Workers in Ghana: 2003-2008

Each line indicates the real log wages of a particular gradeXstep group (e.g. senior medical officers on step 5); each group's wages are normalized to zero in 2003; Source: IPPD Database 


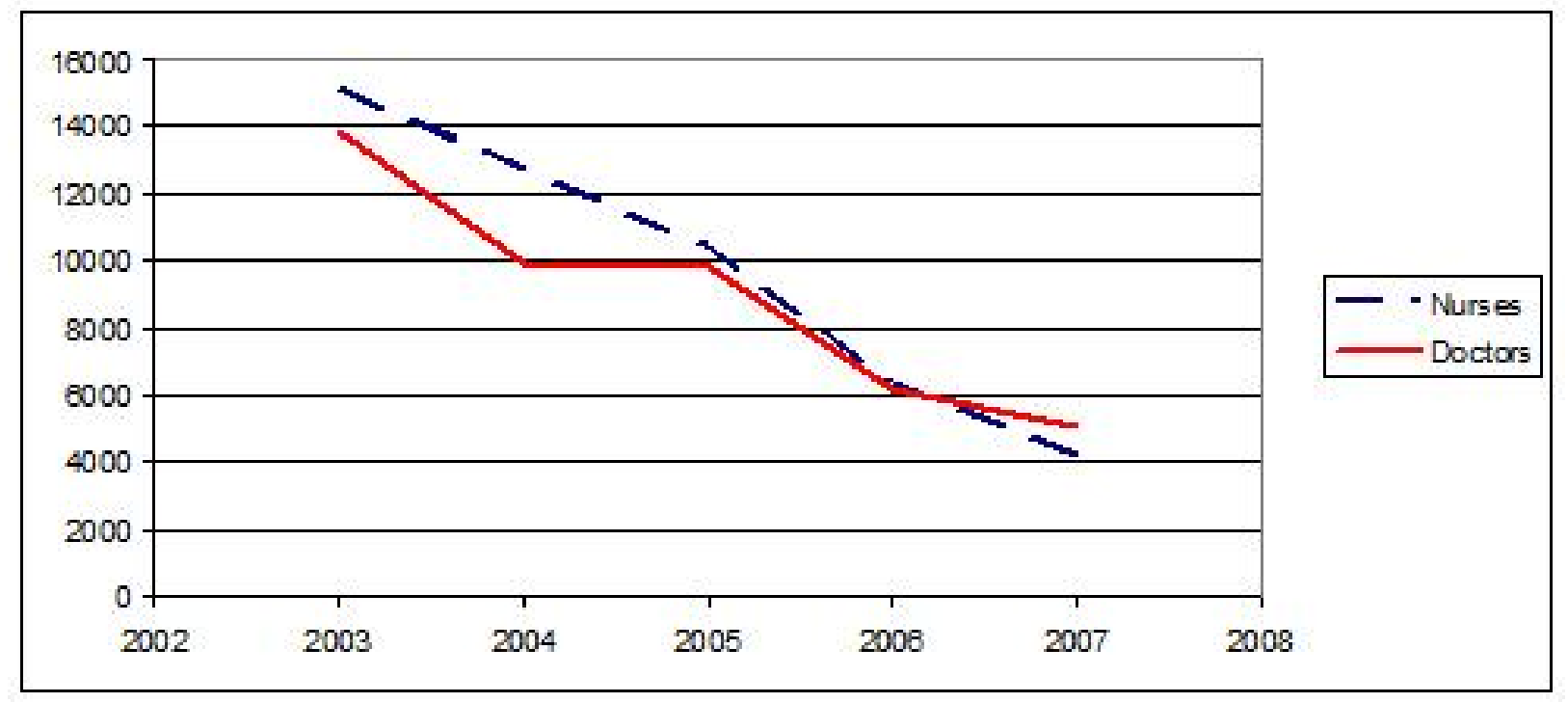

Figure 6: Migration of Health Workers to the UK from All Source Countries Sources: UK General Medical Council and UK Nurses and Midwives Council 